\title{
MRI in the assessment of adipose tissues and muscle composition: how to use it
}

\author{
Florian Alexander Huber ${ }^{1}$, Filippo Del Grande ${ }^{2}$, Stefania Rizzo ${ }^{2}$, Giuseppe Guglielmi ${ }^{3}$, \\ Roman Guggenberger ${ }^{1}$
}

${ }^{1}$ Institute of Diagnostic and Interventional Radiology, University Hospital Zurich, Zurich, Switzerland; ${ }^{2}$ Istituto di imaging della Svizzera Italiana, Regional Hospital of Lugano, Lugano, Switzerland; ${ }^{3}$ Department of Radiology, University of Foggia, Foggia, Italy

Correspondence to: Florian Alexander Huber. Institute of Diagnostic and Interventional Radiology, University Hospital Zurich, Zurich, Switzerland. Email: florian.huber@usz.ch.

\begin{abstract}
Body composition analysis based on the characterization of different tissue compartments is currently experiencing increasing attention by a broad range of medical disciplines for both clinical and research questions. However, body composition profiling (BCP) can be performed utilizing different modalities, which all come along with several technical and diagnostic strengths and limitations, respectively. Magnetic resonance imaging (MRI) demonstrates good soft tissue resolution, high contrast between fat and water, and is free from ionizing radiation. This review article represents an overview of imaging techniques for body composition assessment, focussing on qualitative and quantitative methods of assessing adipose tissue and muscles in MRI.
\end{abstract}

Keywords: Magnetic resonance imaging (MRI); body composition; musculoskeletal system

Submitted Oct 28, 2019. Accepted for publication Jan 19, 2020.

doi: 10.21037 /qims.2020.02.06

View this article at: http://dx.doi.org/10.21037/qims.2020.02.06

\section{Introduction}

The human body has ever attracted different scientific areas in terms of finding methods of how to systematically and reproducibly analyze its constituents on a micro- and macroscopic level. Due to technical progress and new modalities, the concept of body composition profiling (BCP) has gained increasing interest in recent years and has thus experienced various ways of assessment and definition (1). $\mathrm{BCP}$ in its broadest sense describes the composition and distribution of the large compartments in the human body-muscles, adipose tissue, parenchymal organs, bones and blood (2). Magnetic resonance imaging (MRI) with its optimal soft tissue resolution and inherently high contrast between fat and water is an ideal modality for the assessment of adipose tissues and muscle without the use of ionizing radiation. This review article intends to give an overview of BCP emphasizing qualitative and quantitative MR imaging concepts in the assessment of adipose and muscle tissues.

\section{Methods for BCP}

\section{Dual-energy X-ray absorptiometry (DEXA)}

The interest in BCP has started a long time before the invention of MR and imaging in general, an exemplary development was the invention of the body mass index (BMI) in the nineteenth century. However, the need for measures of BCP beyond BMI was early noticed among the radiologic community, and CT-derived volume estimations have been first described as early as in 1984 (3). Dual-energy X-ray absorptiometry (DEXA) is a modality well known for its usability in the setting of osteoporosis quantification. However, DEXA proved comparably well for volume assessment of different body compartments by using only a very limited amount of radiation $(0.5 \mu \mathrm{Sv})(4)$. To date, DEXA is the most popular imaging technique 
Table 1 Exemplary whole-body MRI protocol for sarcopenia assessment (partially adopted from Morone et al. 2017)

\begin{tabular}{|c|c|c|c|c|c|c|}
\hline Sequence & $\begin{array}{l}\text { Acquisition } \\
\text { direction }\end{array}$ & Field of view & $\begin{array}{l}\text { Slice } \\
\text { thickness }\end{array}$ & $\begin{array}{l}\text { Examination } \\
\text { region }\end{array}$ & $\begin{array}{l}\text { Target acquisition } \\
\text { time }\end{array}$ & Specials \\
\hline $\begin{array}{l}\text { 3D or 2D T1-weighted } \\
\text { gradient-echo Dixon } \\
\text { (two-point) }\end{array}$ & $\begin{array}{l}\text { Axial (or } \\
\text { coronal } \\
\text { acquisition) }\end{array}$ & $\begin{array}{l}\text { Largest available (usually } \\
<50 \mathrm{~cm} \times 50 \mathrm{~cm} \text { ) }\end{array}$ & $5-7 \mathrm{~mm}$ & Whole-body & $\sim 10 \min$ & $\begin{array}{l}\text { No coil needed. } \\
\text { Recommended use of } \\
\text { breath-hold sequences }\end{array}$ \\
\hline $\begin{array}{l}\text { T1-weighted multi-echo } \\
\text { Dixon }\end{array}$ & Axial & $\begin{array}{l}\text { Adapted to thigh size } \\
\text { (both sides) }\end{array}$ & $2-3 \mathrm{~mm}$ & $\begin{array}{l}\text { Mid-thigh } \\
\text { (10-20 slices) }\end{array}$ & $\sim 2 \min$ & $\begin{array}{l}\text { Multi-channel body coil. } \\
\text { T2* corrected multi-echo } \\
\text { images may improve } \\
\text { accuracy (19) }\end{array}$ \\
\hline
\end{tabular}

used for BCP. While it can be performed regionally or as a whole-body examination, its current use in musculoskeletal metabolic and geriatric settings is most often focused on the analysis of the appendicular skeletal muscle mass (5). However, DEXA is prone to a series of variations and errors, that may arise from the scanner itself as well as from the subject examined (6). The accuracy of DEXA measurements may have been overestimated for a long time $(7,8)$ and the modality's accuracy depends largely from the system used as well as from the population examined $(6,9)$. To show equivalence to muscle and fat remains difficult (7) and bases on a model with assuming constant fat-free mass hydration of $73 \%$, which can in fact range from $67 \%$ to $85 \%$ (10). As a consequence, repetitive scans of the same person at different states of hydration cause significant differences in classical DEXA measures (11).

\section{Computed tomography (CT)}

CT allows for the attenuation-based depiction of body compartments with high resolution. Besides, it facilitates the segmentation of muscle cross-sectional areas per slice as well as for 3D volume segmentation, e.g., calculation of total muscle mass. As attenuation data are scaled in relation to water (HU 0 ) and thus comparable among different scanners, a threshold-based approach is applied, typically at a range of around -30 to 150 Hounsfield Units (HU) as segmentation mask $(12,13)$. Unlike DEXA, muscle segmentation also allows for macroscopic morphologic assessment of muscle quality. Within the segmented muscle cross-sectional areas, myosteatosis is identified by streaks of negative $\mathrm{HU}$ values and fatty infiltration lowers muscle attenuation as fat voxels by definition have negative HU values (13). However, muscle and fat volume segmentation is time-consuming, which is why CT currently focusses on muscle quantity assessment extrapolated from a single slice, most commonly at the level of the third or fourth lumbar vertebra (13). There is large-scale research that has recently been investigating the automation of muscle areas in CT, enhancing its diagnostic yield in terms of whole-body muscle volume assessment. As for other radiological demands, automation enhanced by artificial intelligence algorithms has already demonstrated the potential for muscle mass segmentation (14). However, the use of CT for this task is naturally associated with substantial radiation dose and therefore usually limited to a specific population and indication, limiting its role for longitudinal observations $(5,15)$.

\section{MRI}

Parallel to advantages in the application of CT for BCP tasks, MRI has gained comparable importance in the assessment of body compartments, muscle mass, and associated anthropometric measures. The technique is free of ionizing radiation and therefore allows repetitive scans in specific longitudinal observations. Furthermore, free from several technical biases or errors in DEXA and CT, MRI has been validated to reliably measure body compartments $(16,17)$, and to perform this task at high accuracy, given a range of quantitative error of $1.1 \%$ to $4.4 \%$ (18). This error may also depend on basic acquisition parameters, such as the use of surface or body coils or other protocol decisions (e.g., continuous moving table acquisition; see Table 1 for exemplary protocol) with implications on signal-to-noise ratio and acquisition time. This must be considered and handled individually, as an error of a few percent may be negligible for certain populations and indications while playing a significant role in e.g., monitoring examinations of athletes. In any case, despite its validity and reliability, MRI currently faces difficulties in availability and ease of use in terms of data assessment. The big advantage of muscle assessment by MRI, namely acquisition of whole-body data, 

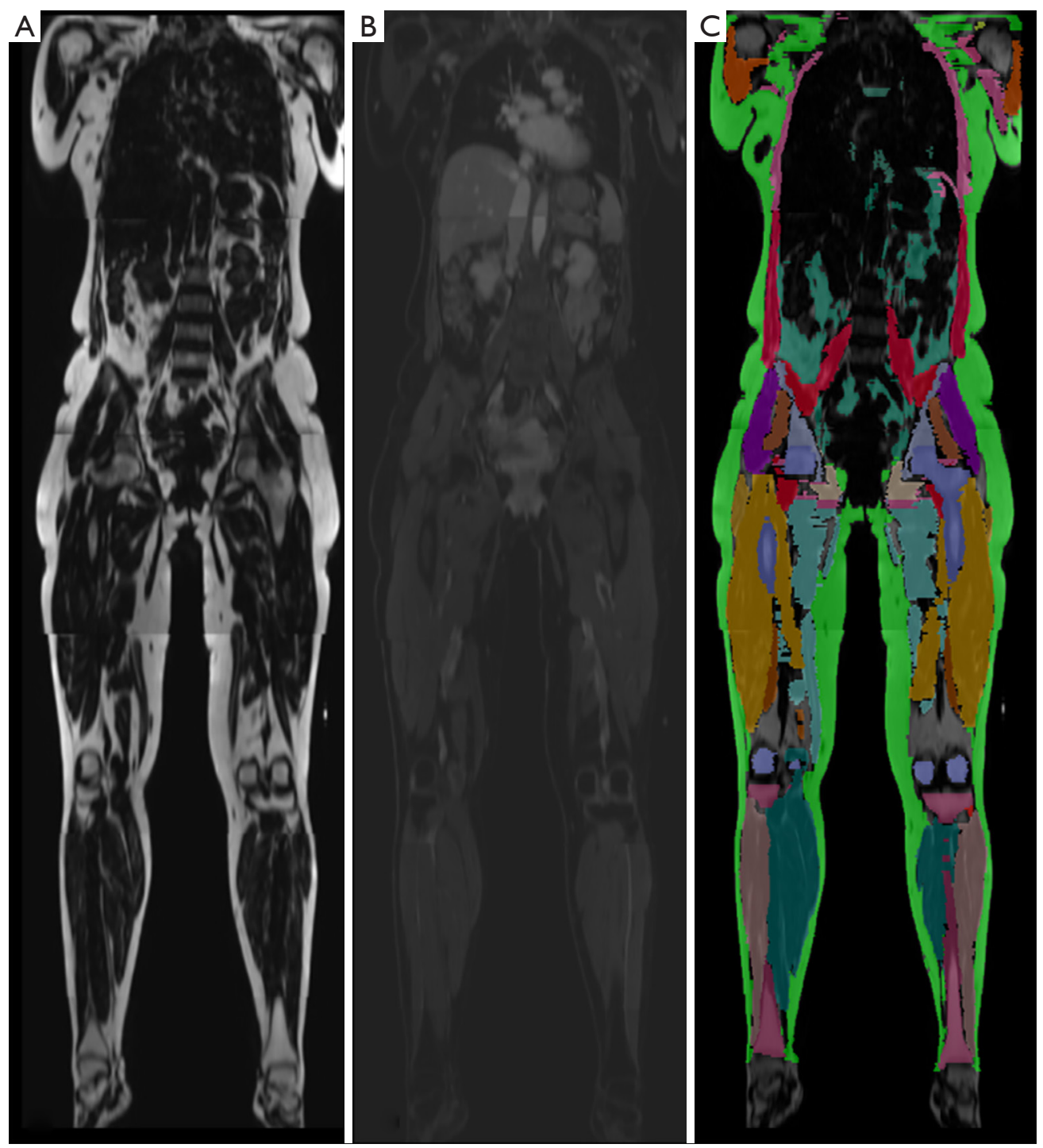

Figure 1 Multiplanar coronal reconstructions of composed (A) fat- and (B) water-only images, as derived from scanner, from an axially acquired T1-weighted whole-body MRI gradient echo sequence using two-point Dixon technique. The images are from a clinically indicated examination of a 34-year-old female patient with mild overweight. The images were post-hoc labor-intensively segmented manually, as shown in the $(\mathrm{C})$ color-coded segmentation image.

demands technically difficult and still time-consuming postprocessing. Manual segmentation, as shown in Figure 1 takes several hours (depending on the volume, accuracy, and detail of segmentation) but is currently not ready-for-use in clinical practice. Numerous automated methods intend to ease whole-body segmentation (20-22), but except for very limited proprietary examples, the majority of $\mathrm{BCP}$ assessment by whole-body MRI is currently performed in research settings employing artificial intelligence for advanced segmentation tasks with promising results (Figure 2).

\section{Standard Spin-Echo MR imaging}

The different MR behavior of macroscopic and cellular fat and water has been extensively described since the very beginnings of animal and clinical MR research (23). Obvious differences in $\mathrm{T} 1-$ and $\mathrm{T} 2$ relaxation times paved the way for qualitative interpretations of fat and water components in tissue and organs in current clinical MR imaging. In acute reactions, muscle tissue usually experiences edematous changes associated with an increase 

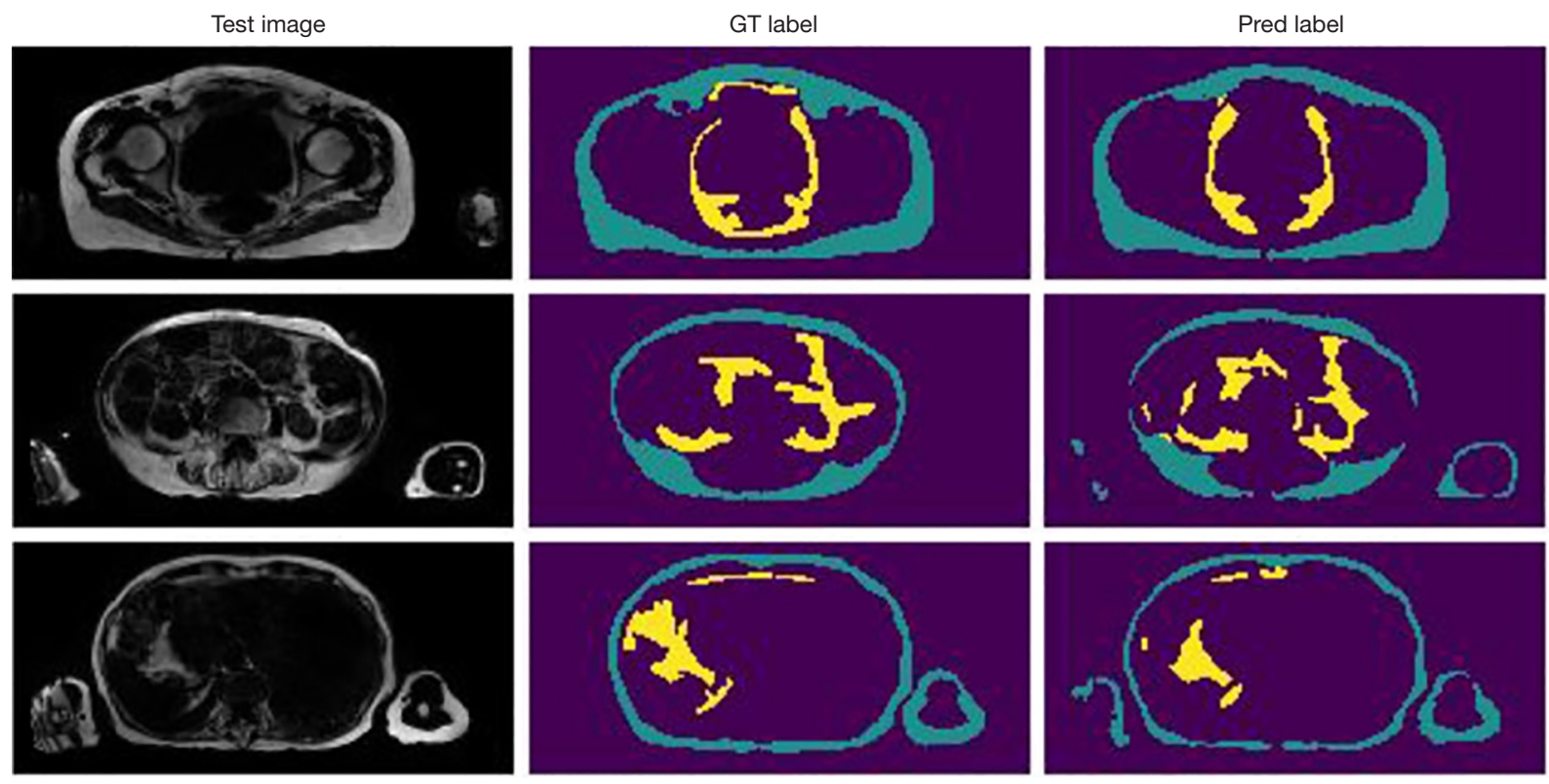

Dice coefficients

Subcutaneous adipose tissue: $0.90 \pm 0.04$, Visceral adipose tissue: $0.74 \pm 0.11$

Figure 2 Exemplary slices of a segmented whole-body MRI of a healthy 50-year-old female, acquired as axial T1-weighted gradient-echo Dixon sequence. The first column shows the original slices, second and third columns are color-labeled maps of the segmentation masks. Adipose tissue was segmented in an experimental approach, differentiating between subcutaneous fat (green) and visceral adipose tissue (yellow). The second and third columns from the left represent manual ground truth (GT) and predicted automatic (Pred) label mask. The comparability was excellent between GT and Pred label using Dice coefficient, however, the agreement was better for subcutaneous fat $(0.90 \pm 0.04)$, compared to visceral fat $(0.74 \pm 0.11)$.

in water and volume, followed by a decrease in water with atrophy and fatty infiltration in chronic changes. While edema can be depicted on fluid sensitive $\mathrm{T} 2$-weighted usually fat-saturated sequences, muscle volume and fatty infiltration can be best seen on non-fat saturated T1 or T2-weighted sequences. Goutallier et al. were the first to describe fatty infiltration grades of the shoulder rotator cuff muscles on a five-point scale, depending on the amount of visually perceivable intramuscular fat on CT images (24). This simple and straight forward concept has been adopted also in MR imaging of the shoulder and different other regions of the body $(25,26)$. Some studies have however also investigated semi-quantitative methods to quantify muscle atrophy and fat infiltration $(26,27)$. According to Davis et al., mere cross-sectional muscle area measurements are more reproducible than semi-quantitative grading with Goutallier classification (28). Advanced quantitative segmentation algorithms in $2 \mathrm{D}$ or $3 \mathrm{D}$ are able to determine fat content and percentage of a muscle area or volume (29).

In addition to muscular volume and fat content assessment, MRI theoretically enables statements about muscle quality regarding muscle fiber type composition based on differences in relaxation times. The relative composition of muscular fiber types I and II, also known as slow- and fast-twitch fibers, determines the functional profile of a muscle and impacts on relaxation behavior. This was until recently only investigated by dissection. Already more than thirty years ago, MRI demonstrated to be excellent for the correlation with pathology in a small cohort (30). However, the underlying principles of tissue differences in $\mathrm{T} 1$ and $\mathrm{T} 2$ times have been thoroughly investigated throughout the last decades and were shown to be dependent on a wide spectrum of influencing factors. Especially edematous changes and sex/agerelated differences have a substantial impact on fiber type composition derived from MR relaxation times $(31,32)$. In fact, the non-specificity of muscular T1 and T2 times limits the ability to reproducibly determine fiber type composition in clinical routine. More recent investigations have however presented encouraging approaches utilizing quantitative 
methods of diffusion-weighted MR (q-space imaging) and were able to differentiate different muscles (by their fiber composition) in mice (33).

\section{Chemical-shift MR imaging}

The principle of chemical shift imaging is based on different precession frequencies of water and fat protons at a certain magnetic field strength. This allows acquiring in- and opposed-phase images where proton spin magnetization vectors at two different echo times (i.e., twopoint technique) are either in equal or opposed direction to each other. Respective signal intensities can then be used to additionally generate fat and water images (Figure 1), resulting in four different image contrasts in total. This principle was first described by Dixon in 1984 (34) and is nowadays widely used in clinical imaging. The Dixon technique due to its robustness, in general, does offer homogeneous fat-saturation over a large field of views, as well as fast MR imaging of large target volumes, e.g., whole-body (wb) MR imaging when used with gradientecho sequences (35-37). However, limitations have to be considered, as especially fast two-point Dixon sequences are prone to $\mathrm{B} 0$-magnetic field inhomogeneity (38). There are however different strategies in reducing this error. On one hand, multi-echo Dixon techniques compensate for these inhomogeneities, allowing to accurately quantify fat content in any image voxel through fat-fraction maps where the grey value of each pixel is proportional to its respective fat-percentage (39). This technique is most widely used for quantification of liver steatosis and has shown to be comparable to a histologic reference standard $(40,41)$. The same technique has also been applied to muscle imaging and in a recent study fatty infiltration of rotator cuff muscles was quantified with isotropic fat-fraction maps from multi-echo $3 \mathrm{D}$-Dixon sequences and correlated with post-operative outcome measures (42), indicating the direction of advanced muscle quality assessment with quantitative MR imaging. On the other hand, certain methods for B0-magnetic field inhomogeneity reduction focus on the use of prospective and retrospective intensity inhomogeneity correction. Exemplarily, Andersson et al. proposed a self-calibrating correction method that allows for the processing of raw as well as normalized images with regard to B0 magnetic field inhomogeneities (43).

In addition to the plain large-scale separation of mainly fat and water containing body compartments, precise assessment of intra- and intermuscular fat can be obtained with higher spatial resolution. Though sometimes misleadingly used synonymously, these two quantitative descriptors of adipose tissues are defined as presence of macroscopic fat within/between fibers of one muscle (i.e., real fatty muscle infiltration, also named "interstitial fat") and of adipose tissue that accumulates between muscle groups underneath the deep fascia, respectively $(44,45)$. While intramuscular fat is more difficult to image, these types of fat deposition are known to be associated differently with several physiologic and pathologic conditions. For example, intramuscular fat content is twice as high after spinal cord injury, compared to healthy controls (46). On the other hand, intermuscular fat is sometimes referred to as "bad" adipose tissue, as it correlates stronger with visceral adipose tissue and is hence linked to the metabolic disease spectrum, and furthermore serves as a good predictor of insulin sensitivity (47). Moreover, over the past two decades, different groups have demonstrated quantitative changes of intramuscular fat in diseases from the spectrum of neuromuscular disorders, most commonly muscular dystrophies (48). Dahlqvist et al., for example, proved that fat fraction derived by chemical shift imaging of paraspinal and other muscles in facioscapulohumeral dystrophy patients, correlated with clinical and genetic disease markers, even when symptoms did not (49). Another group used three-point Dixon for quantification of intramuscular fat fraction in Duchenne muscular dystrophy. The result was a stronger correlation with a validated disease severity score than any other tested clinical examinations, such as isokinetic dynamometry of the knee extensor strength (50).

Dixon technique cannot only generate fat- and waterimages but can also define precise quantitative water and fat fraction maps on a voxel basis. This represents a major benefit compared to CT $(51,52)$ where a certain attenuation/HU value is attributed to each voxel based on the integral of the respective constituents. Hence, the potential fat contribution to a certain attenuation value of one single voxel cannot be clearly identified (53). As the presence of fat even in one small voxel is though known to improve specificity in lesion characterization (53), detection of intravoxel, and more specifically intracellular fat, is of utmost importance and used in several clinical scan protocols, e.g., for liver imaging $(54,55)$, as well as in research settings $(56,57)$.

\section{Diffusion-weighted imaging and MR spectroscopy}

Apart from chemical shift (Dixon-technique) imaging, 
different groups have also assessed muscle quality utilizing diffusion-weighted and diffusion-tensor imaging (DTI) (58-60). In the example of rotator cuff muscles, quantitative fat fractions, as well as different DTIderived parameters, were shown to highly correlate with age-related alterations, which were undetectable by visual reading. The findings were also supported by naturally higher interreader agreements, compared to the readers' rating according to the Goutallier classification system (61). Other groups were also able to show significant correlations between standard DTI measures and functional tests of muscle quality, such as Klupp et al. by comparing paraspinal muscular DTI parameters with measures from an isokinetic dynamometer (62). DTI may also help determine muscle integrity or recovery from bundle tears that can be nicely illustrated by additional tractography but until now DTI has not found its way to large scale applications in clinical routine and largely remains a research tool.

MR spectroscopy attempts to quantify tissue constituents on a molecular level, usually based on $\mathrm{H} 1$-proton signals. While there is a large body of literature about MR spectroscopy application in fat quantification and other tasks of liver imaging $(63,64)$, the technique has also proven its usability in neuroradiologic as well as musculoskeletal settings. In musculoskeletal radiology, standard proton-based MR spectroscopy has mostly been used for the analysis of tumor lesions but also shows significant correlations with the metabolic status of muscular tissue (65). MR spectroscopy does not only allow to assess lactate concentration after muscle exertion (66) but can also accurately determine fat content in a certain volume of interest (VOI). However, this is associated with considerable sample error as a consequence of VOI position variance (67). Only small changes in the VOI position may have a huge impact on accurate fat quantification. The additionally rather long acquisition times and the need for a prospective acquisition, further prevent large scale use of this technique beyond scientific studies. While MR spectroscopy has existed even before clinical MR imaging and is still often considered as the gold standard of volumetric fat quantification $(68,69)$, current clinical investigations predominantly focus on chemical shift imaging (70). Nonetheless, MR spectroscopy is still used frequently in research settings, also due to recent discoveries in the field of in-vivo muscle function assessment with 31-P-spectroscopy $(71,72)$. This has recently allowed for the accurate assessment of muscular metabolic changes in different diseases, revealing altered $\mathrm{pH}$ levels at rest and under exercise in nephropathic type 1 diabetes mellitus patients (73), or identifying three different disease phases in facioscapulohumeral dystrophy (74).

\section{Texture analysis and advanced post-processing}

Among musculoskeletal experts as well as in all other radiologic subspecialties advanced methods of image pattern analysis, termed texture analysis (TA) (75), have been investigated with significant implications on clinical outcome. Pattern recognition may help to find new biomarkers that better correlate with clinical outcomes compared to mere qualitative ratings, e.g., percentage gradings of fatty muscle infiltration $(76,77)$. Moreover, isotropic MR sequences allow for the acquisition of detailed large volume datasets, e.g., of whole muscle groups or even whole-body MR data sets allowing for 3D volume assessment pattern recognition of fatty muscle infiltration, e.g., of the psoas muscle (78). TA may thus produce more reproducible and sophisticated biomarkers of muscle quality than mere qualitative ratings of radiologists.

\section{Clinical applications of MRI for BCP: the present}

The currently used concepts of BCP assessment differ by large regarding technical (i.e., imaging modality) and clinical conditions (i.e., heterogeneity of definition) and are therefore of limited comparability. Despite the trending character of whole-body imaging, it is currently believed that this is one of the main-restricting factors for further clinical applications in metabolic/geriatric settings as well as in oncologic disease monitoring (79).

Nonetheless, MRI may be a very promising BCP assessment method for the future. So far, there is exciting literature on the correlation of MR BCP data with clinical indications and their disease outcomes. Apart from using MR data for evaluation of normal healthy populations (80), athletes or elderly patients (81), it is also significantly associated with classic outcome parameters, e.g., mortality and common laboratory tests, e.g., tumor markers in oncologic $(58,82)$ and metabolic (83-86) patients. In terms of drug-monitoring, studies have demonstrated both positive (87) and negative (88) drug effects on MR-derived BCP measures. Large-scale prospective biobank trials have furthermore had first achievements in phenotyping by imaging, e.g., by linking different BCP types with increased risk of type II diabetes or coronary heart disease (89). 


\section{Sarcopenia}

The most interesting application may however be in the field of sarcopenia. The term sarcopenia, originating from the Greek for "loss of flesh" (sarx penia) is a condition determined by the loss of muscle volume and force and is believed to correlate with higher mortality in geriatric patients among all disease-specific cohorts. Furthermore, sarcopenia seems to be linked to higher mortality, as discovered by an opportunistic screening study in a crosssectional elderly population $(13,90)$.

This condition is defined by three diagnostic criteria: anatomic changes (as reduced calf circumference); loss in muscle quality; decrease physical strength (as reduced grip strength and/or walking speeds). According to recently revised guidelines published by the European Working Group on Sarcopenia in Older People (EWGSOP), sarcopenia in the elderly patient per definition is "probably" present when muscle strength is reduced, "confirmed" by a reduced muscle quality or quantity (depending on the modality in use, e.g., ASMM in MRI), and is believed to be "severe" when physical performance is in addition significantly reduced $(91,92)$. The EWGSOP recommends MRI as one of the imaging modalities to evaluate the confirmation criteria, i.e. muscle quantity or quality. In the last version, the guidelines specifically recommend the utilization of MRI for measuring appendicular skeleton muscle mass, or its related index (ASMMI) for heightadoption, which have been well investigated and extensively discussed in DEXA-related research for the past decades $(5,7,93)$. Moreover, the prevalence of sarcopenia in obese populations has been investigated by Linge $e t$ al., and there's data indicating that even more sophisticated correction for different body constitutions may be respected in future guidelines for criteria of sarcopenia assessment. In any case, MR-derived body markers such as muscle fat infiltration and fat-tissue free muscle volume have been shown to allow for a muscle-specific functional assessment (94).

The current EWGSOP consensus paper focuses on qualitative methods of MRI for muscle BCP profiling (91). Most importantly, intermuscular adipose tissue (Figure 3) often measured at mid-thigh level-is a parameter that has already been investigated extensively using threshold-based measurements in CT (95). When derived from MR images it has also been shown to correlate with mortality and other disease outcome measures (96) and may thus be the focus of further BCP studies. The fact that it is reliable in the assessment of sarcopenic muscles (97) and can be evaluated from a single slice $(98,99)$ may prove beneficial for the use of BCP profiling and muscular assessment with MRI. Common qualitative and quantitative measures of BCP in WB-MRI are as follows:

(I) Fat-related volumes:

* Visceral adipose tissue volume (VAT);

* Subcutaneous adipose tissue (SCAT);

* Pericardial adipose tissue.

(II) Muscle-related volumes:

* Total muscle volume;

* Appendicular skeleton muscle mass (ASMMI).

(III) Muscle quality parameters:

* Intermuscular adipose tissue (IMAT) at mid-thigh level;

* Total cross-sectional area of visualized muscles at the L3 level;

* Total cross-sectional area of psoas muscle at the L4 level.

(IV) Anthropometric and other measures:

* Patient height;

* Circumferences (abdominal, thigh, calf);

* Liver fat fraction.

\section{MRI and BCP: challenges and future}

An increasing number of prospective investigations demonstrated interesting results for whole-body MRI for muscle and fat evaluation. Similarly, the topic of muscle quality and BCP assessment with MRI has gained increasing attention, as shown by a doubled number of publications focusing on fat volume assessment in MRI in the last 5 years $(22)$.

Since on one hand, MR is valid, reliable and reproducible for the assessment of muscle quality and quantity, and on the other hand, first prospective studies have shown promising results for application in preventive medicine and disease (or therapy) monitoring, the time is now to leverage the technique on a clinical routine level.

As typical for novel techniques, several sources of systematic errors and difficulties may be challenging. First, as previously described, data quality and validation are necessary for multi-center comparison. Substantial differences in data acquisition may be corrected posthoc in academic settings but are important limitations to introduce those techniques in routine clinical practice. It is therefore important to establish and provide clinicians and non-academic imaging experts with normative values of BCP measures, specific for races, age and sex and with 

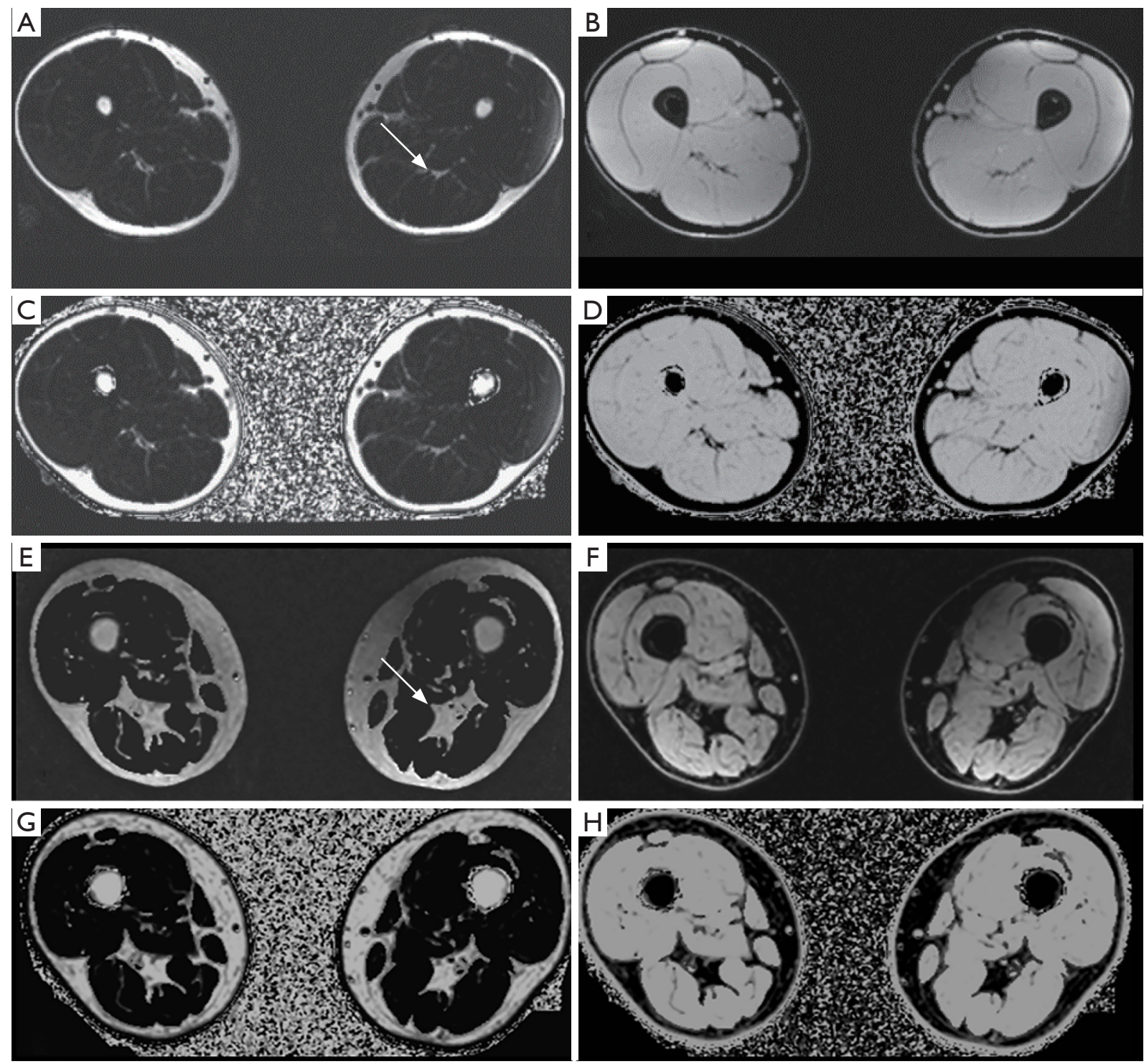

Figure 3 Quantitative methods of muscle quality assessment in MRI. Apart from regular anthropometric measures and cross-sectional area segmentation of (A,E) fat-only- and (B,F) water-only-maps, MRI also allows for sub-visual assessment of muscle quality, e.g., utilizing (C,G) absolute fat-fraction, and $(\mathrm{D}, \mathrm{H})$ water-fraction-maps for analysis of e.g., intra- and intermuscular adipose tissue (arrow in A and E). The images of the two top rows (A,B,C,D) show a mid-thigh slice of axial whole-body scans of a healthy 23-year male student who does on average 6 to 7 hours of sports activities per week. Images (E,F,G,H) show analog representative images of an 82-year-old male individual (sportive activity unknown) with markedly increased areas of intermuscular adipose tissue and in comparison, mild atrophy of the muscular circumference.

appropriate inter-scanner comparability. Furthermore, comparable post-hoc evaluation by automated segmentation software will be important to guarantee data validity. With respect to scan comparability, different groups have made efforts in the recent past to demonstrate excellent multicenter reproducibility as well as reproducibility between different field strengths. On one hand, scan protocol harmonization and user training may be crucial to achieving acceptable reproducibility of manually assessed quantitative measures (100). However, semi-automated assessment, which will be of increasing importance, requires even more sophisticated strategies to allow for multi-scanner and -center comparison. Karlsson et al. therefore demonstrate an accurate and reproducible segmentation method based on 
non-rigid multi-atlas registration of muscle volumes (101), which is also used by a large vendor specialized in body compartment assessment.

Another challenge is the huge amount of MRI data per whole-body scan. A typical whole-body MRI produces 400 to 500 images per composed series (e.g., in-phase, opposedphase, fat-only- or water-only-images). Without robust and fast automated segmentation solutions, BCP assessment with whole-body MRI will be very time consumption up to several hours per patient, which is far more than an average clinical radiologist is allowed to spend for one examination. Alternatives to whole-body solutions may, however, focus on the investigation of data reproducibility that is derived from representative single- or few-slice segmentations. The most representative single slice region of whole-body compartments is believed to be on a lumbar spine level. More specifically, Schweitzer et al. suggest the level of the third lumbar vertebra as optimum in terms of reproducibility and correlation with body compartments (102). As mentioned before, likewise approaches may be a legitimate strategy for a restricted spectrum of clinical tasks, e.g., initial sarcopenia assessment in an opportunistic screening setting. However, the aspect of reduced accuracy must be considered carefully for the majority of clinical demands. Most importantly, more recent studies have proven the inferiority of single-slice technique compared to whole-body compartment assessment, and this method furthermore lacks the required reproducibility for e.g., longitudinal studies, as demonstrated by recent CT-, and more recently MR-related investigations $(103,104)$. Another strategy in assessing these large data amounts is the utilization of automatic registration and segmentation algorithms. Especially within the last few years and rising with the use of artificial intelligence in radiology, several groups have made efforts in testing different segmentation concepts for whole-body imaging, muscle and fat compartment assessment. While the first studies mostly focused on CT images, an increasing body of literature has recently focused on automated segmentation of different regions and for different radiologic subspecialties in MR and CT as well. A recently published review article describes 408 included original papers that aimed to automatically segment tissue (20). For the musculoskeletal system, Dice similarity coefficients around 0.9 are currently being achieved (20). While most of these applications are limited to research questions, it may be expected, that also due to improvements of expertise among the radiologic community regarding implementation of machine learning these algorithms will be part of clinical routine soon.

The acquisition itself has been usually tested in quite homogeneous populations that were able helping to acquire flawless imaging (or else excluded from many studies). However, whole-body muscle assessment is usually performed using a composition of many smaller acquisition stacks. At the levels of the trunk, these series are usually acquired performing breath-holds, not seldom for up to 20 seconds. This is not only challenging in elderly patients due to their reduced functional lung capacities but may remain impossible for intensive care unit patients, a cohort where BCP has significant implications on their nutritional therapy and outcome (95). Even CT has been investigated scarcely for monitoring of nutritional status (105).

Finally, the main challenge remains in the interpretation of image-based results. Sarcopenia is confirmed by imaging findings; however, disease severity is based on physical examination and tests that relate to patients' physical activity. Since normative values may vary throughout different populations and among various types of body constitution (94), the interpretation of relatively low or high measures of muscle quality or volumes is difficult and requires awareness among diagnostic radiologists. Premature use of pathologic ranges may cause false-positive diagnoses with all its consequences, e.g., cost-intensive patient careers and uncertainty of healthy individuals.

\section{Acknowledgments}

Funding: None.

\section{Footnote}

Provenance and Peer Review: With the arrangement by the Guest Editors and the editorial office, this article has been reviewed by external peers.

Conflicts of Interest: All authors have completed the ICMJE uniform disclosure form (available at http://dx.doi. org/10.21037/qims.2020.02.06). The special issue "Body Composition Imaging" was commissioned by the editorial office without any funding or sponsorship. GG served as the unpaid Guest Editor of the special issue and serves as an unpaid editorial board member of Quantitative Imaging in Medicine and Surgery. FDG reports personal fees from Siemens, non-financial support from Siemens, personal fees from Bayer, outside the submitted work. The authors have no other conflicts of interest to declare. 
Open Access Statement: This is an Open Access article distributed in accordance with the Creative Commons Attribution-NonCommercial-NoDerivs 4.0 International License (CC BY-NC-ND 4.0), which permits the noncommercial replication and distribution of the article with the strict proviso that no changes or edits are made and the original work is properly cited (including links to both the formal publication through the relevant DOI and the license). See: https://creativecommons.org/licenses/by-nc-nd/4.0/.

\section{References}

1. Borga M, West J, Bell JD, Harvey NC, Romu T, Heymsfield SB, Dahlqvist Leinhard O. Advanced body composition assessment: from body mass index to body composition profiling. J Investig Med 2018;66:1-9.

2. Fosbøl MØ, Zerahn B. Contemporary methods of body composition measurement. Clin Physiol Funct Imaging 2015;35:81-97.

3. Grauer WO, Moss AA, Cann CE, Goldberg HI. Quantification of body fat distribution in the abdomen using computed tomography. Am J Clin Nutr 1984;39:631-7.

4. Tosato M, Marzetti E, Cesari M, Savera G, Miller RR, Bernabei R, Landi F, Calvani R. Measurement of muscle mass in sarcopenia: from imaging to biochemical markers. Aging Clin Exp Res 2017;29:19-27.

5. Sergi G, Trevisan C, Veronese N, Lucato P, Manzato E. Imaging of sarcopenia. Eur J Radiol 2016;85:1519-24.

6. Nana A, Slater GJ, Stewart AD, Burke LM. Methodology review: using dual-energy X-ray absorptiometry (DXA) for the assessment of body composition in athletes and active people. Int J Sport Nutr Exerc Metab 2015;25:198-215.

7. Shepherd JA, Ng BK, Sommer MJ, Heymsfield SB. Body composition by DXA. Bone 2017;104:101-5.

8. Borrud LG, Flegal KM, Looker AC, Everhart JE, Harris TB, Shepherd JA. Body composition data for individuals 8 years of age and older: U.S. population, 1999-2004. Vital Health Stat 11 2010:1-87.

9. Santos DA, Dawson JA, Matias CN, Rocha PM, Minderico CS, Allison DB, Sardinha LB, Silva AM. Reference values for body composition and anthropometric measurements in athletes. PLoS One 2014;9:e97846.

10. Moore FD, Boyden CM. Body cell mass and limits of hydration of the fat-free body: Their relation to estimated skeletal weight. Ann N Y Acad Sci 1963;110:62-71.

11. Horber FF, Thomi F, Casez JP, Fonteille J, Jaeger P. Impact of hydration status on body composition as measured by dual energy $\mathrm{X}$-ray absorptiometry in normal volunteers and patients on haemodialysis. Br J Radiol 1992;65:895-900.

12. Sjöström L, Kvist H, Cederblad A, Tylén U.

Determination of total adipose tissue and body fat in women by computed tomography, 40K, and tritium. Am J Physiol 1986;250:E736-45.

13. Lenchik L, Boutin RD. Sarcopenia: Beyond Muscle Atrophy and into the New Frontiers of Opportunistic Imaging, Precision Medicine, and Machine Learning. Semin Musculoskelet Radiol 2018;22:307-22.

14. Burns JE, Yao J, Chalhoub D, Chen JJ, Summers RM. A Machine Learning Algorithm to Estimate Sarcopenia on Abdominal CT. Acad Radiol 2020;27:311-20.

15. Woodrow G. Body composition analysis techniques in the aged adult: indications and limitations. Curr Opin Clin Nutr Metab Care 2009;12:8-14.

16. Selberg O, Burchert W, Graubner G, Wenner C, Ehrenheim C, Müller MJ. Determination of anatomical skeletal muscle mass by whole body nuclear magnetic resonance. Basic Life Sci 1993;60:95-7.

17. Lustgarten MS, Fielding RA. Assessment of analytical methods used to measure changes in body composition in the elderly and recommendations for their use in phase II clinical trials. J Nutr Health Aging 2011;15:368-75.

18. Nordez A, Jolivet E, Südhoff I, Bonneau D, de Guise JA, Skalli W. Comparison of methods to assess quadriceps muscle volume using magnetic resonance imaging. J Magn Reson Imaging 2009;30:1116-23.

19. Yoo YH, Kim HS, Lee YH, Yoon CS, Paek MY, Yoo H, Kannengiesser S, Chung TS, Song HT, Suh JS, Kim S. Comparison of Multi-Echo Dixon Methods with Volume Interpolated Breath-Hold Gradient Echo Magnetic Resonance Imaging in Fat-Signal Fraction Quantification of Paravertebral Muscle. Korean J Radiol 2015;16:1086-95.

20. Lenchik L, Heacock L, Weaver AA, Boutin RD, Cook TS, Itri J, Filippi CG, Gullapalli RP, Lee J, Zagurovskaya M, Retson T, Godwin K, Nicholson J, Narayana PA. Automated Segmentation of Tissues Using CT and MRI: A Systematic Review. Acad Radiol 2019;26:1695-706.

21. Fedorov A, Beichel R, Kalpathy-Cramer J, Finet J, FillionRobin JC, Pujol S, Bauer C, Jennings D, Fennessy F, Sonka M, Buatti J, Aylward S, Miller JV, Pieper S, Kikinis R. 3D Slicer as an image computing platform for the Quantitative Imaging Network. Magn Reson Imaging 2012;30:1323-41.

22. Borga $M$. MRI adipose tissue and muscle composition analysis-a review of automation techniques. Br J Radiol 2018;91:20180252.

23. Herfkens R, Davis P, Crooks L, Kaufman L, Price D, 
Miller T, Margulis AR, Watts J, Hoenninger J, Arakawa M, McRee R. Nuclear magnetic resonance imaging of the abnormal live rat and correlations with tissue characteristics. Radiology 1981;141:211-8.

24. Goutallier D, Postel JM, Bernageau J, Lavau L, Voisin MC. Fatty muscle degeneration in cuff ruptures. Pre- and postoperative evaluation by CT scan. Clin Orthop Relat Res 1994:78-83.

25. Jungmann PM, Baum T, Nevitt MC, Nardo L, Gersing AS, Lane NE, McCulloch CE, Rummeny EJ, Link TM. Degeneration in ACL Injured Knees with and without Reconstruction in Relation to Muscle Size and Fat Content-Data from the Osteoarthritis Initiative. PLoS One 2016;11:e0166865.

26. Alizai H, Nardo L, Karampinos DC, Joseph GB, Yap SP, Baum T, Krug R, Majumdar S, Link TM. Comparison of clinical semi-quantitative assessment of muscle fat infiltration with quantitative assessment using chemical shift-based water/fat separation in MR studies of the calf of post-menopausal women. Eur Radiol 2012;22:1592-600.

27. Milisenda JC, Collado MV, Pinal-Fernandez I, Hormaza Jaramillo A, Faruch Bilfeld M, Cano MD, García AI, Tomás X, Grau JM. Correlation between quantitative and semiquantitative magnetic resonance imaging and histopathology findings in dermatomyositis. Clin Exp Rheumatol 2019;37:633-40.

28. Cheung S, Dillon E, Tham SC, Feeley BT, Link TM, Steinbach L, Ma CB. The presence of fatty infiltration in the infraspinatus: its relation with the condition of the supraspinatus tendon. Arthroscopy 2011;27:463-70.

29. Davis DL, Kesler T, Gilotra MN, Almardawi R, Hasan SA, Gullapalli RP, Zhuo J. Quantification of shoulder muscle intramuscular fatty infiltration on T1-weighted MRI: a viable alternative to the Goutallier classification system. Skeletal Radiol 2019;48:535-41.

30. Kuno S, Katsuta S, Inouye T, Anno I, Matsumoto K, Akisada M. Relationship between MR relaxation time and muscle fiber composition. Radiology 1988;169:567-8.

31. Budzik JF, Balbi V, Verclytte S, Pansini V, Le Thuc V, Cotten A. Diffusion tensor imaging in musculoskeletal disorders. Radiographics 2014;34:E56-72.

32. Galbán CJ, Maderwald S, Stock F, Ladd ME. Age-related changes in skeletal muscle as detected by diffusion tensor magnetic resonance imaging. J Gerontol A Biol Sci Med Sci 2007;62:453-8.

33. Hata J, Nakashima D, Tsuji O, Fujiyoshi K, Yasutake K, Sera Y, Komaki Y, Hikishima K, Nagura T, Matsumoto M, Okano H, Nakamura M. Noninvasive technique to evaluate the muscle fiber characteristics using q-space imaging. PLoS One 2019;14:e0214805.

34. Dixon WT. Simple proton spectroscopic imaging. Radiology 1984;153:189-94.

35. Pasoglou V, Michoux N, Larbi A, Van Nieuwenhove S, Lecouvet F. Whole Body MRI and oncology: recent major advances. Br J Radiol 2018;91:20170664.

36. Bray TJP, Singh S, Latifoltojar A, Rajesparan K, Rahman F, Narayanan P, Naaseri S, Lopes A, Bainbridge A, Punwani S, Hall-Craggs MA. Diagnostic utility of whole body Dixon MRI in multiple myeloma: A multi-reader study. PLoS One 2017;12:e0180562.

37. Ulbrich EJ, Nanz D, Leinhard OD, Marcon M, Fischer MA. Whole-body adipose tissue and lean muscle volumes and their distribution across gender and age: MR-derived normative values in a normal-weight Swiss population. Magn Reson Med 2018;79:449-58.

38. Ma J. Dixon techniques for water and fat imaging. J Magn Reson Imaging 2008;28:543-58.

39. Kellman P, Hernando D, Shah S, Zuehlsdorff S, Jerecic R, Mancini C, Liang ZP, Arai AE. Multiecho dixon fat and water separation method for detecting fibrofatty infiltration in the myocardium. Magn Reson Med 2009;61:215-21.

40. Heiken JP, Lee JK, Dixon WT. Fatty infiltration of the liver: evaluation by proton spectroscopic imaging. Radiology 2019;47:3080-8.

41. Hayashi T, Saitoh S, Takahashi J, Tsuji Y, Ikeda K, Kobayashi M, Kawamura Y, Fujii T, Inoue M, Miyati T, Kumada H.

Hepatic fat quantification using the two-point Dixon method and fat color maps based on non-alcoholic fatty liver disease activity score. Hepatol Res 2017;47:455-64.

42. Wieser K, Joshy J, Filli L, Kriechling P, Sutter R, Fürnstahl P, Valdivieso P, Wyss S, Meyer DC, Flück M, Gerber C. Changes of Supraspinatus Muscle Volume and Fat Fraction After Successful or Failed Arthroscopic Rotator Cuff Repair. Am J Sports Med 2019:363546519876289.

43. Andersson T, Romu T, Karlsson A, Norén B, Forsgren MF, Smedby Ö, Kechagias S, Almer S, Lundberg P, Borga M, Leinhard OD. Consistent intensity inhomogeneity correction in water-fat MRI. J Magn Reson Imaging 2015;42:468-76.

44. Ogawa M, Lester R, Akima H, Gorgey AS. Quantification of intermuscular and intramuscular adipose tissue using magnetic resonance imaging after neurodegenerative disorders. Neural Regen Res 2017;12:2100-5.

45. Yoshiko A, Yamauchi K, Kato T, Ishida K, Koike T, Oshida Y, Akima H. Effects of post-fracture non-weight-bearing 
immobilization on muscle atrophy, intramuscular and intermuscular adipose tissues in the thigh and calf. Skeletal Radiol 2018;47:1541-9.

46. Gorgey AS, Dudley GA. Skeletal muscle atrophy and increased intramuscular fat after incomplete spinal cord injury. Spinal Cord 2007;45:304-9.

47. Hausman GJ, Basu U, Du M, Fernyhough-Culver M, Dodson MV. Intermuscular and intramuscular adipose tissues: Bad vs. good adipose tissues. Adipocyte 2014;3:242-55.

48. Burakiewicz J, Sinclair CDJ, Fischer D, Walter GA, Kan HE, Hollingsworth KG. Quantifying fat replacement of muscle by quantitative MRI in muscular dystrophy. $\mathrm{J}$ Neurol 2017;264:2053-67.

49. Dahlqvist JR, Vissing CR, Thomsen C, Vissing J. Severe paraspinal muscle involvement in facioscapulohumeral muscular dystrophy. Neurology 2014;83:1178-83.

50. Wren TA, Bluml S, Tseng-Ong L, Gilsanz V. Three-point technique of fat quantification of muscle tissue as a marker of disease progression in Duchenne muscular dystrophy: preliminary study. AJR Am J Roentgenol 2008;190:W8-12.

51. Pokharel SS, Macura KJ, Kamel IR, Zaheer A. Current MR imaging lipid detection techniques for diagnosis of lesions in the abdomen and pelvis. Radiographics 2013;33:681-702.

52. Bley TA, Wieben O, François CJ, Brittain JH, Reeder SB. Fat and water magnetic resonance imaging. J Magn Reson Imaging 2010;31:4-18.

53. Ünal E, Karaosmanoğlu AD, Akata D, Özmen MN, Karçaaltıncaba M. Invisible fat on CT: making it visible by MRI. Diagn Interv Radiol 2016;22:133-40.

54. Earls JP, Krinsky GA. Abdominal and pelvic applications of opposed-phase MR imaging. AJR Am J Roentgenol 1997;169:1071-7.

55. Basaran C, Karcaaltincaba M, Akata D, Karabulut N, Akinci D, Ozmen M, Akhan O. Fat-containing lesions of the liver: cross-sectional imaging findings with emphasis on MRI. AJR Am J Roentgenol 2005;184:1103-10.

56. Li SR, Pui MH, Guo Y, Wang HJ, Guan J, Zhang XL, Pan WB. Efficacy of 3D VIBE Dixon fat quantification for differentiating clear-cell from non-clear-cell renal cell carcinoma. Clin Radiol 2018;73:975-80.

57. Partridge SC, Singer L, Sun R, Wilmes LJ, Klifa CS, Lehman CD, Hylton NM. Diffusion-weighted MRI: influence of intravoxel fat signal and breast density on breast tumor conspicuity and apparent diffusion coefficient measurements. Magn Reson Imaging 2011;29:1215-21.

58. Boutin RD, Yao L, Canter RJ, Lenchik L. Sarcopenia: Current Concepts and Imaging Implications. AJR Am J
Roentgenol 2015;205:W255-66.

59. Ermetici F, Briganti S, Delnevo A, Cannaò P, Leo GD, Benedini S, Terruzzi I, Sardanelli F, Luzi L. Bone marrow fat contributes to insulin sensitivity and adiponectin secretion in premenopausal women. Endocrine 2018;59:410-8.

60. Messina C, Maffi G, Vitale JA, Ulivieri FM, Guglielmi G, Sconfienza LM. Diagnostic imaging of osteoporosis and sarcopenia: a narrative review. Quant Imaging Med Surg 2018;8:86-99.

61. Kälin PS, Huber FA, Hamie QM, Issler LS, FarshadAmacker NA, Ulbrich EJ, Guggenberger R. Quantitative MRI of Visually Intact Rotator Cuff Muscles by Multiecho Dixon-Based Fat Quantification and Diffusion Tensor Imaging. J Magn Reson Imaging 2019;49:109-17.

62. Klupp E, Cervantes B, Schlaeger S, Inhuber S, Kreuzpointer F, Schwirtz A, Rohrmeier A, Dieckmeyer M, Hedderich DM, Diefenbach MN, Freitag F, Rummeny EJ, Zimmer C, Kirschke JS, Karampinos DC, Baum T. Paraspinal Muscle DTI Metrics Predict Muscle Strength. J Magn Reson Imaging 2019;50:816-23.

63. Traussnigg S, Kienbacher C, Gajdošík M, Valkovič L, Halilbasic E, Stift J, Rechling C, Hofer H, Steindl-Munda P, Ferenci P, Wrba F, Trattnig S, Krššák M, Trauner M. Ultra-high-field magnetic resonance spectroscopy in non-alcoholic fatty liver disease: Novel mechanistic and diagnostic insights of energy metabolism in nonalcoholic steatohepatitis and advanced fibrosis. Liver Int 2017;37:1544-53

64. Wáng YXJ, Wang X, Wu P, Wang Y, Chen W, Chen H, Li $\mathrm{J}$. Topics on quantitative liver magnetic resonance imaging. Quant Imaging Med Surg 2019;9:1840-90.

65. Subhawong TK, Wang X, Durand DJ, Jacobs MA, Carrino JA, Machado AJ, Fayad LM. Proton MR spectroscopy in metabolic assessment of musculoskeletal lesions. AJR Am J Roentgenol 2012;198:162-72.

66. Pan JW, Hamm JR, Hetherington HP, Rothman DL, Shulman RG. Correlation of lactate and $\mathrm{pH}$ in human skeletal muscle after exercise by 1H NMR. Magn Reson Med 1991;20:57-65.

67. Fischer MA, Nanz D, Shimakawa A, Schirmer T, Guggenberger R, Chhabra A, Carrino JA, Andreisek G. Quantification of muscle fat in patients with low back pain: comparison of multi-echo MR imaging with single-voxel MR spectroscopy. Radiology 2013;266:555-63.

68. Agten CA, Rosskopf AB, Gerber C, Pfirrmann CW. Quantification of early fatty infiltration of the rotator cuff muscles: comparison of multi-echo Dixon with singlevoxel MR spectroscopy. Eur Radiol 2016;26:3719-27. 
69. Aisen AM, Chenevert TL. MR spectroscopy: clinical perspective. Radiology 1989;173:593-9.

70. Grimm A, Meyer H, Nickel MD, Nittka M, Raithel E, Chaudry O, Friedberger A, Uder M, Kemmler W, Engelke K, Quick HH. A Comparison between 6-point Dixon MRI and MR Spectroscopy to Quantify Muscle Fat in the Thigh of Subjects with Sarcopenia. J Frailty Aging 2019;8:21-6.

71. Giannesini B, Izquierdo M, Le Fur Y, Cozzone PJ, Fingerle J, Himber J, Künnecke B, Von Kienlin M, Bendahan D. New experimental setup for studying strictly noninvasively skeletal muscle function in rat using $1 \mathrm{H}$-magnetic resonance (MR) imaging and 31P-MR spectroscopy. Magn Reson Med 2005;54:1058-64.

72. Valkovič L, Chmelík M, Krššák M. In-vivo 31P-MRS of skeletal muscle and liver: A way for non-invasive assessment of their metabolism. Anal Biochem 2017;529:193-215.

73. Sedivy P, Dezortova M, Drobny M, Vlasakova Z, Herynek V, Hajek M. Differences in muscle metabolism in patients with type I diabetes - influence of gender and nephropathy studied by (31)P MR spectroscopy. Physiol Res 2018;67:433-41.

74. Janssen BH, Voet NB, Nabuurs CI, Kan HE, de Rooy JW, Geurts AC, Padberg GW, van Engelen BG, Heerschap A. Distinct disease phases in muscles of facioscapulohumeral dystrophy patients identified by MR detected fat infiltration. PLoS One 2014;9:e85416.

75. Lubner MG, Smith AD, Sandrasegaran K, Sahani DV, Pickhardt PJ. CT Texture Analysis: Definitions, Applications, Biologic Correlates, and Challenges. Radiographics 2017;37:1483-503.

76. Mannil M, Burgstaller JM, Thanabalasingam A, Winklhofer S, Betz M, Held U, Guggenberger R. Texture analysis of paraspinal musculature in MRI of the lumbar spine: analysis of the lumbar stenosis outcome study (LSOS) data. Skeletal Radiol 2018;47:947-54.

77. Mannil M, Burgstaller JM, Held U, Farshad M, Guggenberger R. Correlation of texture analysis of paraspinal musculature on MRI with different clinical endpoints: Lumbar Stenosis Outcome Study (LSOS). Eur Radiol 2019;29:22-30.

78. Huang CWC, Tseng IJ, Yang SW, Lin YK, Chan WP. Lumbar muscle volume in postmenopausal women with osteoporotic compression fractures: quantitative measurement using MRI. Eur Radiol 2019;29:4999-5006.

79. Morone M, Bali MA, Tunariu N, Messiou C, Blackledge M, Grazioli L, Koh DM. Whole-Body MRI: Current Applications in Oncology. AJR Am J Roentgenol
2017;209:W336-49.

80. Pourhassan M, Glüer CC, Pick P, Tigges W, Müller MJ. Impact of weight loss-associated changes in detailed body composition as assessed by whole-body MRI on plasma insulin levels and homeostatis model assessment index. Eur J Clin Nutr 2017;71:212-8.

81. Cameron J, McPhee JS, Jones DA, Degens H. Fiveyear longitudinal changes in thigh muscle mass of septuagenarian men and women assessed with DXA and MRI. Aging Clin Exp Res 2020;32:617-24.

82. Doyle SL, Donohoe CL, Lysaght J, Reynolds JV. Visceral obesity, metabolic syndrome, insulin resistance and cancer. Proc Nutr Soc 2012;71:181-9.

83. Neeland IJ, Ayers CR, Rohatgi AK, Turer AT, Berry JD, Das SR, Vega GL, Khera A, McGuire DK, Grundy SM, de Lemos JA. Associations of visceral and abdominal subcutaneous adipose tissue with markers of cardiac and metabolic risk in obese adults. Obesity (Silver Spring) 2013;21:E439-47.

84. Lee JJ, Pedley A, Hoffmann U, Massaro JM, Fox CS. Association of Changes in Abdominal Fat Quantity and Quality With Incident Cardiovascular Disease Risk Factors. J Am Coll Cardiol 2016;68:1509-21.

85. Bamberg F, Hetterich H, Rospleszcz S, Lorbeer R, Auweter SD, Schlett CL, Schafnitzel A, Bayerl C, Schindler A, Saam T, Müller-Peltzer K, Sommer W, Zitzelsberger T, Machann J, Ingrisch M, Selder S, Rathmann W, Heier M, Linkohr B, Meisinger C, Weber C, Ertl-Wagner B, Massberg S, Reiser MF, Peters A. Subclinical Disease Burden as Assessed by Whole-Body MRI in Subjects With Prediabetes, Subjects With Diabetes, and Normal Control Subjects From the General Population: The KORA-MRI Study. Diabetes 2017;66:158-69.

86. Britton KA, Massaro JM, Murabito JM, Kreger BE, Hoffmann U, Fox CS. Body fat distribution, incident cardiovascular disease, cancer, and all-cause mortality. J Am Coll Cardiol 2013;62:921-5.

87. Rooks DS, Laurent D, Praestgaard J, Rasmussen S, Bartlett M, Tankó LB. Effect of bimagrumab on thigh muscle volume and composition in men with casting-induced atrophy. J Cachexia Sarcopenia Muscle 2017;8:727-34.

88. Bolan PJ, Arentsen L, Sueblinvong T, Zhang Y, Moeller S, Carter JS, Downs LS, Ghebre R, Yee D, Froelich J, Hui S. Water-fat MRI for assessing changes in bone marrow composition due to radiation and chemotherapy in gynecologic cancer patients. J Magn Reson Imaging 2013;38:1578-84.

89. Linge J, Borga M, West J, Tuthill T, Miller MR, 
Dumitriu A, Thomas EL, Romu T, Tunón P, Bell JD, Dahlqvist Leinhard O. Body Composition Profiling in the UK Biobank Imaging Study. Obesity (Silver Spring) 2018;26:1785-95.

90. Lenchik L, Lenoir KM, Tan J, Boutin RD, Callahan KE, Kritchevsky SB, Wells BJ. Opportunistic Measurement of Skeletal Muscle Size and Muscle Attenuation on Computed Tomography Predicts 1-Year Mortality in Medicare Patients. J Gerontol A Biol Sci Med Sci 2019;74:1063-9.

91. Cruz-Jentoft AJ, Bahat G, Bauer J, Boirie Y, Bruyère O, Cederholm T, Cooper C, Landi F, Rolland Y, Sayer AA, Schneider SM, Sieber CC, Topinkova E, Vandewoude M, Visser M, Zamboni M, Writing Group for the European Working Group on Sarcopenia in Older People 2 (EWGSOP2) atEGfE. Sarcopenia: revised European consensus on definition and diagnosis. Age Ageing 2019;48:16-31.

92. Cruz-Jentoft AJ, Baeyens JP, Bauer JM, Boirie Y, Cederholm T, Landi F, Martin FC, Michel JP, Rolland Y, Schneider SM, Topinková E, Vandewoude M, Zamboni M, People EWGoSiO. Sarcopenia: European consensus on definition and diagnosis: Report of the European Working Group on Sarcopenia in Older People. Age Ageing 2010;39:412-23.

93. Boyer L, Chouaïd C, Bastuji-Garin S, Marcos E, Margarit L, Le Corvoisier P, Vervoitte L, Hamidou L, Frih L, Audureau E, Covali-Noroc A, Andujar P, Saakashvili Z, Lino A, Ghaleh B, Hue S, Derumeaux G, Housset B, Dubois-Randé JL, Boczkowski J, Maitre B, Adnot S. Aging-related systemic manifestations in COPD patients and cigarette smokers. PLoS One 2015;10:e121539.

94. Linge J, Heymsfield SB, Dahlqvist Leinhard O. On the Definition of Sarcopenia in the Presence of Aging and Obesity-Initial Results from UK Biobank. J Gerontol A Biol Sci Med Sci 2020;75:1309-16.

95. Looijaard WG, Dekker IM, Stapel SN, Girbes AR, Twisk JW, Oudemans-van Straaten HM, Weijs PJ. Skeletal muscle quality as assessed by CT-derived skeletal muscle density is associated with 6-month mortality in mechanically ventilated critically ill patients. Crit Care 2016;20:386.

96. Addison O, Marcus RL, Lastayo PC, Ryan AS. Intermuscular fat: a review of the consequences and causes. Int J Endocrinol 2014;2014:309570.

97. Heymsfield SB, Gonzalez MC, Lu J, Jia G, Zheng J. Skeletal muscle mass and quality: evolution of modern measurement concepts in the context of sarcopenia. Proc Nutr Soc 2015;74:355-66.
98. Ruan XY, Gallagher D, Harris T, Albu J, Heymsfield S, Kuznia P, Heshka S. Estimating whole body intermuscular adipose tissue from single cross-sectional magnetic resonance images. J Appl Physiol (1985) 2007;102:748-54.

99. Boettcher M, Machann J, Stefan N, Thamer C, Häring HU, Claussen CD, Fritsche A, Schick F. Intermuscular adipose tissue (IMAT): association with other adipose tissue compartments and insulin sensitivity. J Magn Reson Imaging 2009;29:1340-5.

100. Schlaffke L, Rehmann R, Rohm M, Otto LAM, de Luca A, Burakiewicz J, Baligand C, Monte J, den Harder C, Hooijmans MT, Nederveen A, Schlaeger S, Weidlich D, Karampinos DC, Stouge A, Vaeggemose M, D'Angelo MG, Arrigoni F, Kan HE, Froeling M. Multi-center evaluation of stability and reproducibility of quantitative MRI measures in healthy calf muscles. NMR Biomed 2019;32:e4119.

101. Karlsson A, Rosander J, Romu T, Tallberg J, Grönqvist A, Borga M, Dahlqvist Leinhard O. Automatic and quantitative assessment of regional muscle volume by multi-atlas segmentation using whole-body water-fat MRI. J Magn Reson Imaging 2015;41:1558-69.

102.Schweitzer L, Geisler C, Pourhassan M, Braun W, Glüer CC, Bosy-Westphal A, Müller MJ. What is the best reference site for a single MRI slice to assess whole-body skeletal muscle and adipose tissue volumes in healthy adults? Am J Clin Nutr 2015;102:58-65.

103. Shen W, Chen J, Gantz M, Velasquez G, Punyanitya M, Heymsfield SB. A single MRI slice does not accurately predict visceral and subcutaneous adipose tissue changes during weight loss. Obesity (Silver Spring) 2012;20:2458-63.

104. Thomas EL, Bell JD. Influence of undersampling on magnetic resonance imaging measurements of intraabdominal adipose tissue. Int J Obes Relat Metab Disord 2003;27:211-8.

105. Berger MM, Reintam-Blaser A, Calder PC, Casaer M, Hiesmayr MJ, Mayer K, Montejo JC, Pichard C, Preiser JC, van Zanten ARH, Bischoff SC, Singer P. Monitoring nutrition in the ICU. Clin Nutr 2019;38:584-93.

Cite this article as: Huber FA, Del Grande F, Rizzo S, Guglielmi G, Guggenberger R. MRI in the assessment of adipose tissues and muscle composition: how to use it. Quant Imaging Med Surg 2020;10(8):1636-1649. doi: 10.21037/ qims.2020.02.06 